\title{
Hot topic: Innovative lactation-stage-dependent prediction of methane emissions from milk mid-infrared spectra
}

\author{
A. Vanlierde, ${ }^{* 1}$ M.-L. Vanrobays,$\dagger^{1}$ F. Dehareng, ${ }^{*}$ E. Froidmont, $\ddagger$ H. Soyeurt, $\dagger$ S. McParland,§ E. Lewis, $\S$ \\ M. H. Deighton,\# F. GrandI,II M. Kreuzer,II B. Gredler, I P. Dardenne, ${ }^{*}$ and N. Genglert ${ }^{2}$ \\ *Walloon Agricultural Research Centre, Valorization of Agricultural Products Department, 5030 Gembloux, Belgium \\ †Agriculture, Bio-engineering and Chemistry Department, Gembloux Agro-Bio Tech, University of Liège, 5030 Gembloux, Belgium \\ $\ddagger$ Walloon Agricultural Research Centre, Production and Sectors Department, 5030 Gembloux, Belgium \\ $\S$ Teagasc, Animal and Grassland Research and Innovation Centre, Moorepark, Fermoy, Co. Cork, Ireland \\ \#Agriculture Research Division, Department of Economic Development, Jobs, Transport and Resources, Ellinbank Centre, Ellinbank, \\ 3821 Victoria, Australia \\ IIETH Zürich, Institute of Agricultural Sciences, 8092 Zürich, Switzerland \\ TQualitas AG, 6300 Zug, Switzerland
}

\section{ABSTRACT}

The main goal of this study was to develop, apply, and validate a new method to predict an indicator for $\mathrm{CH}_{4}$ eructed by dairy cows using milk mid-infrared (MIR) spectra. A novel feature of this model was the consideration of lactation stage to reflect changes in the metabolic status of the cow. A total of 446 daily $\mathrm{CH}_{4}$ measurements were obtained using the $\mathrm{SF}_{6}$ method on 142 Jersey, Holstein, and Holstein-Jersey cows. The corresponding milk samples were collected during these $\mathrm{CH}_{4}$ measurements and were analyzed using MIR spectroscopy. A first derivative was applied to the milk MIR spectra. To validate the novel calibration equation incorporating days in milk (DIM), 2 calibration processes were developed: the first was based only on $\mathrm{CH}_{4}$ measurements and milk MIR spectra (independent of lactation stage; ILS); the second included milk MIR spectra and DIM information (dependent on lactation stage; DLS) by using linear and quadratic modified Legendre polynomials. The coefficients of determination of ILS and DLS equations were 0.77 and 0.75 , respectively, with standard error of calibration of $63 \mathrm{~g} / \mathrm{d}$ of $\mathrm{CH}_{4}$ for both calibration equations. These equations were applied to 1,674,763 milk MIR spectra from Holstein cows in the first 3 parities and between 5 and 365 DIM. The average $\mathrm{CH}_{4}$ indicators were 428,444 , and $448 \mathrm{~g} / \mathrm{d}$ by ILS and 444,467 , and $471 \mathrm{~g} / \mathrm{d}$ by DLS for cows in first, second, and third lactation, respectively. Behavior of the DLS indicator throughout the lactations was in agreement with the literature with values increasing between 0 and 100 DIM and decreasing thereafter. Conversely, the ILS indicator of $\mathrm{CH}_{4}$ emission decreased at

Received June 3, 2014.

Accepted March 31, 2015.

${ }^{1}$ These authors contributed equally to this work.

${ }^{2}$ Corresponding author: nicolas.gengler@ulg.ac.be the beginning of the lactation and increased until the end of the lactation, which differs from the literature. Therefore, the DLS indicator seems to better reflect biological processes that drive $\mathrm{CH}_{4}$ emissions than the ILS indicator. The ILS and DLS equations were applied to an independent data set, which included 59 respiration chamber measurements of $\mathrm{CH}_{4}$ obtained from animals of a different breed across a different production system. Results indicated that the DLS equation was much more robust than the ILS equation allowing development of indicators of $\mathrm{CH}_{4}$ emissions by dairy cows. Integration of DIM information into the prediction equation was found to be a good strategy to obtain biologically meaningful $\mathrm{CH}_{4}$ values from lactating cows by accounting for biological changes that occur throughout the lactation.

Key words: dairy cattle, mid-infrared, methane, lactation stage, milk

\section{Hot Topic}

Feed costs are the largest expense in dairy production and limit the profitability of dairy farms (Vallimont et al., 2011). Methane emissions, besides contributing to the carbon footprint of dairy products, represent a loss of use of energy intake (Johnson and Johnson, 1995). Therefore, interest is growing in mitigating $\mathrm{CH}_{4}$ emissions, thereby reducing environmental footprint but also potentially improving feed efficiency and reducing related feed costs. Most of the $\mathrm{CH}_{4}$ emitted by cattle is eructed. However, the measurement of eructed $\mathrm{CH}_{4}$ emissions is difficult and expensive. To mitigate these emissions, it is important to have a cheap, fast, and robust method to measure the $\mathrm{CH}_{4}$ emissions of individual cows on a large scale. Traits that can be easily recorded and that are correlated with $\mathrm{CH}_{4}$ emissions are therefore of interest. De novo synthesis of milk FA in the mammary gland is dependent on the products of 
ruminal fermentation (Chilliard et al., 2000), as is the production of eructed $\mathrm{CH}_{4}$ (Chilliard et al., 2009; Dijkstra et al., 2011). Hence, changes in the FA profile of milk fat may be relevant. Because mid-infrared (MIR) spectrometry is known to be useful in predicting milk FA contents (Soyeurt et al., 2011), Dehareng et al. (2012) developed prediction equations to obtain individual $\mathrm{CH}_{4}$ emissions of dairy cows directly from milk MIR spectra. However, results obtained using those equations did not fit with what was expected from the literature, showing the lowest emissions in early lactation and an increase thereafter. A hypothesis could be that milk FA profile, and therefore the relationship between $\mathrm{CH}_{4}$ and MIR spectra, is strongly influenced by the evolution of body-tissue mobilization during lactation, leading to suboptimal predictions. Consequently, MIR prediction equations that incorporate stage of lactation may better take into account the metabolic changes that occur throughout lactation. The objective of this study was to develop, apply, and test on MIR data, a novel and readily adoptable method that includes lactation stage as a proxy for metabolic status in the $\mathrm{CH}_{4}$ prediction equation based on milk MIR spectra. The ability of the novel method to predict a $\mathrm{CH}_{4}$ indicator was tested on a completely unrelated external data set.

\section{Development of Mid-Infrared-Based $\mathrm{CH}_{4}$ Indicators}

Methane Reference Measurements. Measurements of $\mathrm{CH}_{4}$ emissions from dairy cows were obtained from the Teagasc Animal and Grassland Research and Innovation Center (Moorepark, Co. Cork, Ireland), the Walloon Agricultural Research Centre (Gembloux, Belgium), and from one commercial herd in Belgium. A total of 446 individual daily $\mathrm{CH}_{4}$ measurements were recorded: 270 Irish records from 117 individual Holstein, Jersey, and Holstein-Jersey crossbred cows, including 49 first-, 30 second-, and 38 third- or laterparity animals; and 176 Walloon records from 25 Holstein cows including 10 first-, 6 second-, and 9 third- or later-parity animals. Measurements were conducted at different lactation stages (Table 1). This data set of $\mathrm{CH}_{4}$ values was characterized by a minimum of 180 $\mathrm{g} / \mathrm{d}$, a maximum of $942 \mathrm{~g} / \mathrm{d}$, a mean of $416 \mathrm{~g} / \mathrm{d}$, and a standard deviation of $128 \mathrm{~g} / \mathrm{d}$. To achieve the largest possible variability required for robust calibration equations, cows were fed with very different diets: grass or high silage diets (maize vs. grass silages), with or without linseed supplementation, and synchronized or not in terms of fermentable energy and nitrogen supplies in the rumen. Daily $\mathrm{CH}_{4}$ emissions of individual cows were determined using the sulfur hexafluoride $\left(\mathrm{SF}_{6}\right)$ tracer gas technique with a gas collection period of $24 \mathrm{~h}$. Details about the methodology used to collect the breath samples of emitted gases and to measure the $\mathrm{SF}_{6}$ and the $\mathrm{CH}_{4}$ content were described by Dehareng et al. (2012). By using $\mathrm{CH}_{4}$ emission data collected from different countries, environments, and feeding strategies, an increase in the variability of $\mathrm{CH}_{4}$ emission was expected, ensuring improved robustness of the equation developed to predict $\mathrm{CH}_{4}$ emissions.

Spectral Reference Data. On each day of the $\mathrm{CH}_{4}$ measurements, a $40-\mathrm{mL}$ aliquot of milk was collected from each cow at both the morning and evening milking. Sodium azide $(0.32 \mathrm{~g} / \mathrm{L})$ was added to each sample before storage at $4^{\circ} \mathrm{C}$ and MIR analysis was subsequently undertaken using a MilkoScan FT6000 spectrometer (Foss, Hillerød, Denmark). Two spectrometers were used for this study, one located at the Teagasc Animal and Grassland Research and Innovation Center (Co. Cork, Ireland) and one at the milk laboratory Comité du Lait (Battice, Belgium). Two spectra were available per day and per $\mathrm{CH}_{4}$ measurement. To obtain 1 spectrum per $\mathrm{CH}_{4}$ record, the 2 spectra were averaged proportionally to the milk yield at each milking.

Development of $\mathrm{CH}_{4}$ Indicator Equations. To determine the effect of inclusion of DIM information as a predictor variable, 2 prediction equations were developed using independent calibration processes; $\mathrm{CH}_{4}$ was the dependent variable for both equations. The first prediction equation was independent of lactation stage (ILS) and included milk MIR spectra as the sole pre-

Table 1. Distribution of the number of records in the calibration data set, by parity and stage of lactation of cows, and country from where records were obtained, used to develop methane emissions indicators

\begin{tabular}{|c|c|c|c|c|c|c|}
\hline \multirow[b]{3}{*}{ Classes of DIM } & \multicolumn{6}{|c|}{ Parity } \\
\hline & \multicolumn{2}{|c|}{ First } & \multicolumn{2}{|c|}{ Second } & \multicolumn{2}{|c|}{ Third or greater } \\
\hline & Ireland & Belgium & Ireland & Belgium & Ireland & Belgium \\
\hline 1 to 50 DIM & 1 & 7 & 1 & 0 & 4 & 0 \\
\hline 51 to 100 DIM & 19 & 8 & 21 & 16 & 31 & 0 \\
\hline 101 to 150 DIM & 31 & 13 & 19 & 10 & 27 & 15 \\
\hline 151 to 200 DIM & 46 & 19 & 18 & 6 & 12 & 3 \\
\hline$>200$ DIM & 19 & 33 & 13 & 6 & 8 & 40 \\
\hline
\end{tabular}


dictor variable. The ILS equation was therefore equivalent to that developed by Dehareng et al. (2012). The second prediction equation was dependent on lactation stage (DLS) and included both DIM of each cow to describe the stage of lactation at which the data were collected and MIR spectra as predictor variables.

The calibration data set contained 446 average daily milk spectral records matched with the daily $\mathrm{CH}_{4}$ emission data of each cow on the day the milk sample was collected. Following observation of the spectral variation, the calibrations were developed from 3 spectral regions: between wavenumbers 968 and $1,577 \mathrm{~cm}^{-1}, 1,720$ and $1,809 \mathrm{~cm}^{-1}$, and 2,561 and $2,966 \mathrm{~cm}^{-1}$, respectively $(\mathrm{n}=289$ data points). Using Winisi software (Foss, Hillerød, Denmark), partial least squares regression was used to develop the MIR $\mathrm{CH}_{4}$ prediction equation after the application of a first derivative (Soyeurt et al., 2011) on the recorded spectral data (hereafter called the ILS spectral data set).

To obtain the DLS calibration equation, each first derivative value of the spectrum was multiplied by (1) a constant (i.e., 1), (2) a linear $(\sqrt{3} \times x)$, and (3) a quadratic $\left[\sqrt{5 / 4} \times\left(3 x^{2}-1\right)\right]$ modified Legendre polynomial (Gengler et al., 1999), where

$$
\mathrm{x}=-1+2[(\mathrm{DIM}-5) /(365-5)] .
$$

Through this process, a modified spectral data set was generated containing 867 data points (289 data points for each constant, linear, and quadratic part) referred to hereafter as the DLS spectral data set. The linear and the quadratic parts of these modified spectra take into account the lactation stage of cows. Because the constant component was 1, the ILS spectral data set was a subset of the DLS spectral data set. The range of application of the DLS equation was between 5 and 365 DIM given the range of lactation covered in the definition of the Legendre polynomials.

To check the independence of residuals between the corresponding measured and predicted ruminal $\mathrm{CH}_{4}$ emissions of cows (DLS and ILS MIR $\mathrm{CH}_{4}$ indicators) across DIM, a linear regression of those residuals on DIM was fitted using the PROC REG procedure (SAS Institute Inc., Cary, NC).

\section{Application of Prediction Equations to Milk Mid- Infrared Spectra}

A general requirement for any $\mathrm{CH}_{4}$ indicator and, therefore, the underlying prediction equation, is that its observed evolution and variation make biological sense when applied to a data set of measured spectra that cover a similar range of spectral variability as the reference data. To test the observed evolution and variation of $\mathrm{CH}_{4}$ indicators, the developed MIR $\mathrm{CH}_{4}$ prediction equations (ILS and DLS equations) were applied to the spectral database of milk recording collected in the Walloon Region of Belgium since 2007. These milk samples are routinely collected by the Walloon Breeding Association (Ciney, Belgium) during farm milk recording and the spectral data records were generated by the milk laboratory Comité du Lait (Battice, Belgium) using a MIR MilkoScan FT6000 spectrometer (Foss, Hillerød, Denmark). The ILS equation was directly applied to the milk spectra after applying the first derivative. To use the DLS equation, the same pretreatment to each spectrum was used as in the creation of the DLS spectral data set (i.e., first derivative and multiplication by modified Legendre polynomials). Equations were applied only to records from Holstein cows in the first 3 lactations and collected between 5 and 365 DIM (the range of modified Legendre polynomials) leading to a total of 1,951,669 spectral records. To achieve a spectral data range that is well underpinned by spectra used for the calibration, the data set was cleared from spectrally too different data using the standardized Mahalanobis distance $(\mathbf{G H})$. This value was calculated between each considered spectrum and those used for the calibration to estimate how different a MIR spectrum of the Walloon milk-recording data set was from spectra of the calibration set. Spectra with a GH greater than 3 were not used in this study, representing only $14 \%$ of the 1,951,669 spectra according to the huge variability of Walloon spectra and relatively limited variability of the prediction equations. Extreme values of predicted $\mathrm{CH}_{4}$ were also detected and estimates of $\mathrm{CH}_{4}$ below 150 and above $950 \mathrm{~g} / \mathrm{d}$ of $\mathrm{CH}_{4}$ (the extended minimum and maximum were obtained by subtracting or adding $50 \mathrm{~g} / \mathrm{d}$ to minimum and maximum of actual $\mathrm{CH}_{4}$ measurements from the data set of calibration as shown in Figure 1) were deleted. The final data set contained 1,674,763 MIR spectra and milk yield records collected between January 2007 and March 2014 in 1,654 herds from 176,692 cows including $1,649,750$ and $1,672,441$ ILS and DLS $\mathrm{CH}_{4}$ records, respectively. The normality of the distributions for ILS and DLS $\mathrm{CH}_{4}$ indicators from MIR were studied based on the calculation of Skewness and Kurtosis parameters using PROC UNIVARIATE in the SAS system (SAS Institute Inc., Cary, NC).

The observed variability of ILS and DLS MIR $\mathrm{CH}_{4}$ indicators should reflect several effects known to influence $\mathrm{CH}_{4}$ production such as effects of herd, year and month of test-date, lactation number, lactation stage, animal, and milk yield. Therefore, these effects were investigated for the MIR predicted $\mathrm{CH}_{4}$ traits using the following model: 


$$
\begin{aligned}
y_{\text {pqrstu }}= & \mu+h_{p} \times y_{q}+m o_{r}+l_{s} \times d_{t}+c_{u} \\
& +m \alpha+(m \times m) \beta+e_{\text {pqrstu }},
\end{aligned}
$$

where $y_{\text {pqrstu }}$ was the predicted $\mathrm{CH}_{4}$ trait $(1,649,750$ and $1,672,441$ for the ILS and DLS indicators described above); $\mu$ was the general mean; $h_{p} \times y_{q}$ was the crossed fixed effect of herd $p$ and year of test-date $q(8 \mathrm{yr}$ from 2007 to 2014); $m o_{r}$ was the fixed effect of month $r ; l_{s} \times$ $d_{t}$ was the crossed fixed effect of lactation number $s(3$ classes: first, second, and third lactations) and lactation stage $t$ (18 classes of 20 DIM from 5 to 365 DIM, the last class including $365 \mathrm{DIM}) ; c_{u}$ was the random effect of cow $u ; m$ was the daily milk yield $(\mathrm{kg} / \mathrm{d}) ; \alpha$ was the linear regression coefficient on $m$; $\beta$ was the quadratic regression coefficient on $m$; and $e_{\text {pqrstu }}$ was the associated random residual. The milk yield effect was included in the model to avoid a potential artifact due to milk yield. Variance components were estimated using the EM-REML and AI-REML algorithms implemented in the REMLF90 and AIREMLF90 software packages, and $\hat{\mathrm{y}}$ and the $l_{s} \times d_{t}$ effect were estimated using the preconditioned conjugate gradient algorithm as implemented in the BLUP90IOD software (Misztal, 2012). The root mean square error (RMSE) and the mean absolute error (MAE) of ILS and DLS indicators were computed as follows (Willmott and Matsuura, 2005):

$$
\begin{aligned}
\text { RMSE } & =\sqrt{\frac{\sum_{i=1}^{n}\left|\varepsilon_{i}\right|^{2}}{n}}, \\
\text { MAE } & =\frac{\sum_{i=1}^{n}\left|\varepsilon_{i}\right|}{n},
\end{aligned}
$$

where $n$ was the number of data, $\varepsilon_{i}$ was the difference between $\hat{y}$ and DLS or ILS indicators for the $i$ th observation. The RMSE and MAE were divided by the calibration coefficient of determination $\left(\mathbf{R}^{2} \mathbf{c}\right)$ of prediction equations to approximate RMSE and MAE of $\hat{y}$ (from DLS and ILS indicators) and direct measurements of $\mathrm{CH}_{4}$ emissions.

\section{Independent Comparison of Methane Indicators with Actual Measurements}

A small calibration data set with specific breeds, feed, and $\mathrm{CH}_{4}$ measurement method was used to develop the prediction equations. However, the different sources of variation of milk composition interact during lactation. An independent comparison (correlations, bias, RMSE, and MAE) of ILS, and DLS $\mathrm{CH}_{4}$ indicator values with actual $\mathrm{CH}_{4}$ measurements from an independent data set was undertaken to assess if the DLS prediction equation was able to disentangle the captured sources of variation in a sufficient manner.

Moreover, to test whether or not the introduction of DLS calibration coefficients was capturing more than only a similarity in the lactation curve shape, a polynomial regression of measured $\mathrm{CH}_{4}$ based only on DIM was fitted without milk MIR spectra. This was done using a multiple regression of the $446 \mathrm{CH}_{4}$ reference measurements (calibration data set) on the 3 regression variables constant, linear, quadratic modified Legendre polynomial of lactation stage, hereafter called regression on lactation stage (RLS). By doing this, the $\mathrm{CH}_{4}$ measurements were linked to 3 regression variables including only DIM information instead of the 289 and 867 data points used for the ILS and DLS equations,

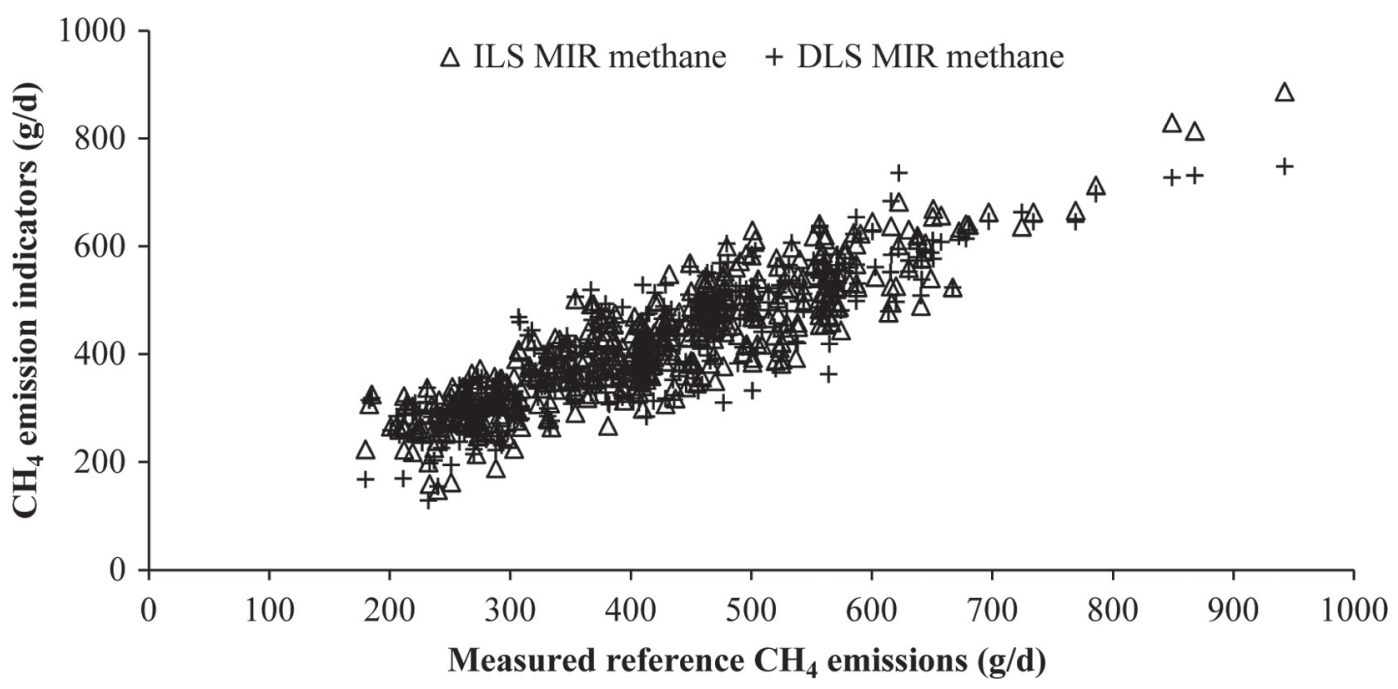

Figure 1. Relationship between measured reference $\mathrm{CH}_{4}$ emissions of cows from the calibration data set and the corresponding indicators of these emissions from mid-infrared (MIR) spectra obtained from the equations independent of lactation stage (ILS) or dependent on lactation stage (DLS). 
respectively. Through this strategy, RLS equation excluded milk MIR spectra information, whereas ILS and DLS equations included this information. The RLS equation was then applied on an independent data set described hereafter to assess if a simple polynomial regression of measured $\mathrm{CH}_{4}$ on DIM would capture the major part of intra-lactation variability of $\mathrm{CH}_{4}$.

A total of 60 respiration chamber measurements of $\mathrm{CH}_{4}$ were obtained from studies made at the AgrovetStrickhof research station (Lindau-Eschikon, Switzerland). These records were collected during $2 \mathrm{~d}$ in open-circuit chambers described in detail by Buehler and Wanner (2012) using 30 lactating cows, and milk collected at that period was analyzed by MIR spectroscopy. These data were of a clearly different origin compared with the calibration data as they were obtained from different breed (Brown-Swiss), feeding system [half were exclusively fed on forage (grass hay, corn silage, and pellets made from artificially dried grass), and the other half received limited amounts of concentrate in addition to the same forage mix], and method of $\mathrm{CH}_{4}$ measurement (chambers). Following application of the GH edit used on the commercial spectral data, one record was removed, leaving 59 spectra available for this study. The ILS, DLS, and RLS equations were applied on these data. Correlation, RMSE, and MAE between actual $\mathrm{CH}_{4}$ measurements and corresponding $\mathrm{CH}_{4}$ indicators were computed.

\section{Results and Discussion}

Development of $\mathrm{CH}_{4}$ Indicator Prediction Equations. The average value for the 446 reference $\mathrm{CH}_{4}$ measurements was $416 \mathrm{~g}$ of $\mathrm{CH}_{4} / \mathrm{d}$ with a standard deviation of $128 \mathrm{~g} / \mathrm{d}$. The coefficient of variation of $31 \%$ suggested a good variability of the studied trait. Figure 1 shows the relationship between the measured and predicted $\mathrm{CH}_{4}$ data (i.e., ILS and DLS MIR $\mathrm{CH}_{4}$ indicators) used in the calibration process. The ILS equation had a $R^{2} c$ of 0.77 with a standard error of calibration (SEC) of $63 \mathrm{~g} / \mathrm{d}$. The $\mathrm{R}^{2} \mathrm{c}$ and SEC of the DLS equation were 0.75 and $63 \mathrm{~g} / \mathrm{d}$, respectively. Based on the statistical calibration parameters, the ILS and DLS equations showed very similar abilities to predict the eructed $\mathrm{CH}_{4}$. Residuals between corresponding $\mathrm{CH}_{4}$ measurements and predicted $\mathrm{CH}_{4}$ emissions of dairy cows (ILS or DLS MIR $\mathrm{CH}_{4}$ indicators) across DIM are shown in Figure 2. Using linear regression of residuals on DIM, the regression coefficients for the DLS residuals were closer to 0 than those obtained for the ILS residuals [ILS residual $=0.1032( \pm 0.0459)$ DIM -15.801 $( \pm 7.551)$, and DLS residual $=-0.0011( \pm 0.0490)$ DIM $+0.1662( \pm 8.067)]$. As regression coefficients were close to 0 , residuals of the DLS indicator showed a bet- ter fit over the lactation because the residuals were less influenced by DIM than the ILS indicator.

Descriptive Statistics of Indicators When Computed on Field Data. After application of the ILS prediction equation to the Walloon milk recording spectral MIR database, the average indicators of daily $\mathrm{CH}_{4}$ emissions were $428( \pm 141), 444( \pm 144)$, and $448( \pm 144) \mathrm{g} / \mathrm{d}$ for cows in first, second, and third lactation, respectively. The average indicators of $\mathrm{CH}_{4}$ emissions obtained from the DLS equation were 444 $( \pm 73), 467( \pm 75)$, and $471( \pm 77) \mathrm{g} / \mathrm{d}$ for first-, second-, and third-parity cows, respectively. These values were within the range of $\mathrm{CH}_{4}$ measurements reported in the literature (e.g., Aguerre et al., 2011; van Zijderveld et al., 2011; Garnsworthy et al., 2012). The variability of the DLS MIR $\mathrm{CH}_{4}$ indicator values was lower than that obtained using the ILS equation. Skewness and Kurtosis parameters of MIR $\mathrm{CH}_{4}$ indicators were low $(0.27$ and -0.36 for ILS and -0.18 and 0.93 for DLS, respectively), suggesting an approximate normal distribution of the studied traits. More values for the ILS indicator were considered out of the range of the calibration in the final data set (less than 150 and greater than 950 $\mathrm{g} / \mathrm{d}$ of $\mathrm{CH}_{4}$ ) compared with those estimated using the DLS equation ( $1.5 \%$ vs. $0.1 \%$ of the $1,674,763$ records, respectively).

Modeling Methane Indicators Traits. Both the ILS and DLS MIR $\mathrm{CH}_{4}$ indicators were significantly affected by all studied fixed effects (i.e., herd $\times$ year of test-day, month of test-day, lactation number $\times$ lactation stage, and milk yield). The residual variance obtained from the estimation of variance components of the ILS indicator was higher than the residual variance of the DLS indicator (10,280 vs. $3,183 \mathrm{~g}^{2}$, respectively). Compared with those obtained using the ILS equation, DLS values conserved more of the intra-cow variability as the associated repeatability (relative cow variance) was $0.15( \pm 0.001)$ for DLS indicators compared with $0.04( \pm 0.000)$ for ILS indicators. As expected, given these results, adjusted RMSE and MAE of DLS indicators were lower than those of ILS indicators (RMSE of 81 and $135 \mathrm{~g} / \mathrm{d}$ of $\mathrm{CH}_{4}$ and MAE of 61 and 103 $\mathrm{g} / \mathrm{d}$ of $\mathrm{CH}_{4}$ for DLS and ILS indicators, respectively). These results indicate that ILS indicator values, even after fitting fixed effects, had a much higher overall variance. Also, the ILS indicator did not retain the expected intra-cow repeatability as did DLS. Therefore, the DLS indicator appeared to reflect better biological processes than the ILS indicator. Figure 3 shows $l_{s} \times$ $d_{t}$ effect solutions on predicted $\mathrm{CH}_{4}$ emissions of cows in first-, second-, and third-parity for 18 classes of 20 DIM. Through the use of the model (1) described previously, observed differences were corrected for all other effects, including milk yield. Both ILS and DLS indi- 


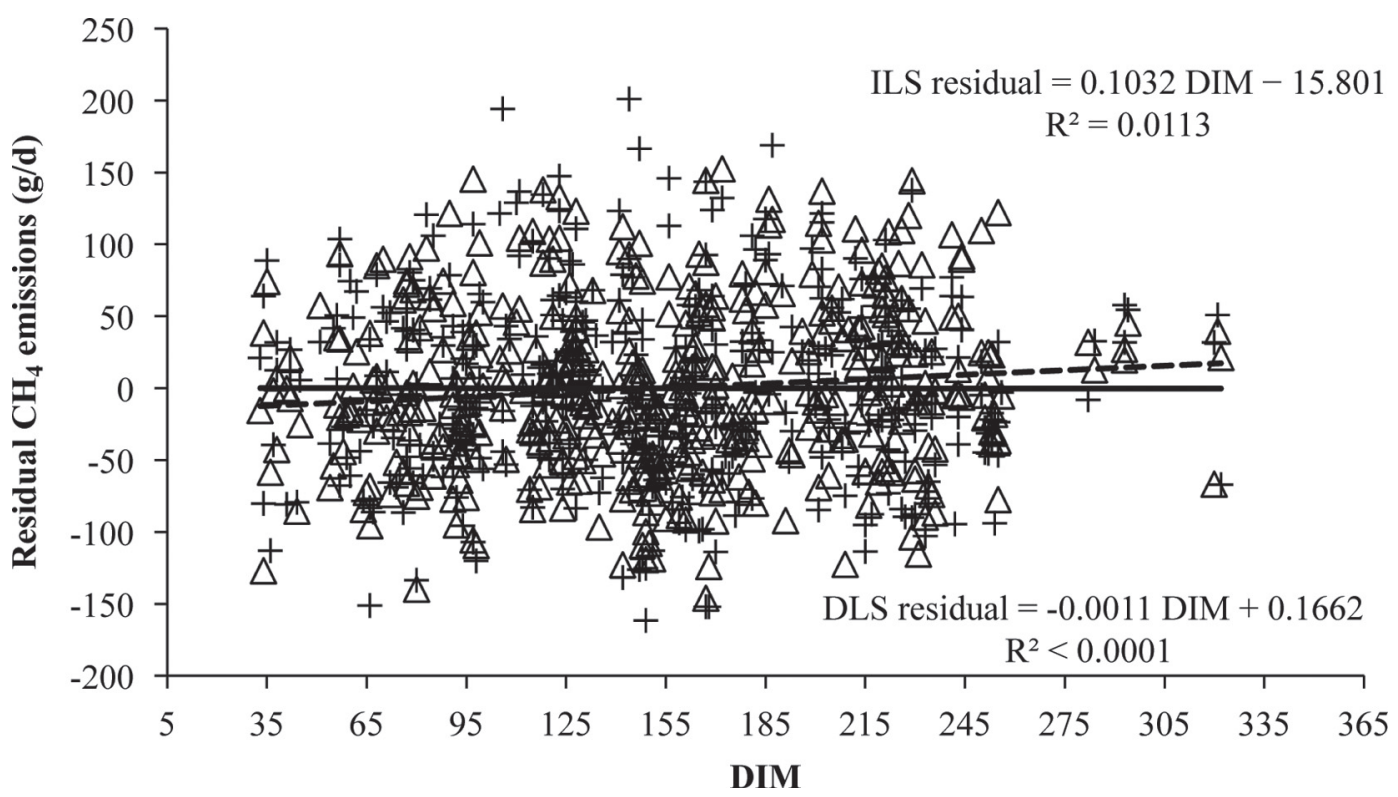

Figure 2. Residuals between corresponding reference $\mathrm{CH}_{4}$ measurements and $\mathrm{CH}_{4}$ emissions indicators of dairy cows across DIM obtained from the calibration process. Indicators of $\mathrm{CH}_{4}$ emissions were calculated by applying prediction equations that were independent of (ILS; $\Delta$ ) or dependent on (DLS; +) lactation stage. Linear trends of residuals (ILS - - -, or DLS -) are also indicated.

cators of multiparous cows appear to be higher than those of primiparous cows as expected. The pattern of DLS values throughout lactation showed an increase during the first 15 wk of lactation followed by a decrease thereafter. In contrast, ILS values decreased at the beginning of lactation and then increased until the end of the lactation. The pattern of the DLS indicator of $\mathrm{CH}_{4}$ emissions was similar to the pattern obtained by Garnsworthy et al. (2012). Actually, this curve is expected as it is known that an increase in feed intake takes place in cows postpartum (e.g., Berry et al., 2007) and feed intake is strongly positively associated with $\mathrm{CH}_{4}$ emissions (Mills et al., 2003). By the joint fitting of milk yield the observed pattern in Figure 3 should reflect the corrected effect of lactation stage on $\mathrm{CH}_{4}$ emission and not a correlated effect from the evolution of milk yield over the lactation. Results support the hypothesis that the difference between the pattern of ILS and DLS indicator could be explained by the fact that the DLS equation better accounts for biological changes by integrating modified Legendre polynomials related to DIM. Regression solutions for milk yield were also used as a way to assess the biological meaning of indicators. These solutions for the DLS indicator were as expected with $1.52 \mathrm{~g} / \mathrm{kg}$ and $-0.04 \mathrm{~g} / \mathrm{kg}^{2}$ for the linear and the quadratic regression coefficient on milk, respectively. Therefore, these results emphasized the expected link between daily $\mathrm{CH}_{4}$ and milk yield. However, solutions for ILS were unexpected with $-0.05 \mathrm{~g} /$ $\mathrm{kg}$ and $-0.02 \mathrm{~g} / \mathrm{kg}^{2}$ for the linear and the quadratic re- gression coefficient on milk, respectively. This result is another indication that ILS did not adequately predict the expected increase in $\mathrm{CH}_{4}$ emission with milk yield.

Independent Comparison of Methane Indicators with Actual Measurements. Correlations (bias) between actual independent $\mathrm{CH}_{4}$ measurements from respiration chambers and ILS, DLS, and $\mathrm{RLS} \mathrm{CH}_{4}$ indicators were $0.09\left(-53 \mathrm{~g} / \mathrm{d}\right.$ of $\left.\mathrm{CH}_{4}\right), 0.48(-52 \mathrm{~g} / \mathrm{d}$ of $\left.\mathrm{CH}_{4}\right)$, and $-0.29\left(47 \mathrm{~g} / \mathrm{d}\right.$ of $\left.\mathrm{CH}_{4}\right)$, respectively. The observed values for RMSE (MAE) were 113 (89), 90 (68), and 102 (80) g/d of $\mathrm{CH}_{4}$ for the ILS, DLS, and RLS indicators, respectively. These results indicate that the DLS indicator prediction equation was much more robust than the ILS equation. When comparing with the results obtained using the RLS prediction, the DLS indicator also seemed to better describe the intralactation variability in the actual $\mathrm{CH}_{4}$ measurements. Therefore, these results indicate that the DLS indicator was capturing more than only similarities in lactation curve shapes, as did RLS.

Additionally, it has to be stressed that this comparison was done in a completely different setting (e.g., breed, feed, $\mathrm{CH}_{4}$ measurement method). Therefore, even if a correlation of the DLS indicator with actual $\mathrm{CH}_{4}$ measurements of 0.48 might seem low, this result is close to expectations. These expectations could be approximated as the product between the square root of $\mathrm{R}^{2} \mathrm{c}$ of the DLS equation (i.e., 0.75), the correlation between $\mathrm{CH}_{4}$ measurements from chambers and $\mathrm{SF}_{6}$ method [ $\sim 0.80$ as reported by Muñoz et al. (2012)], and 

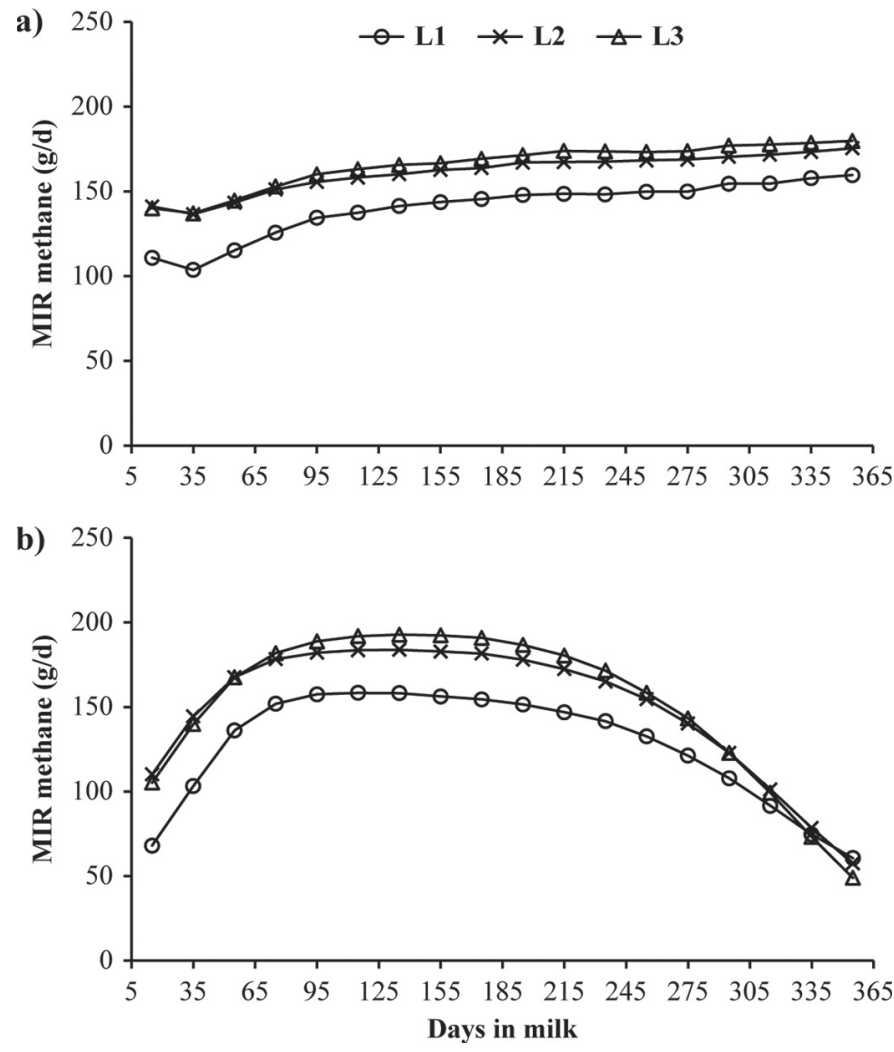

Figure 3. Crossed fixed effect solutions of lactation number and lactation stage on $\mathrm{CH}_{4}$ emissions (g/d) of first- (L1), second- (L2), and third-lactation (L3) Holstein cows for each class of DIM (18 classes of $20 \mathrm{~d}$ in milk) predicted from lactation-stage-independent (a) and lactation-stage-dependent (b) prediction equations applied to milk mid-infrared (MIR) spectra from the spectral database related to the Walloon milk recording.

the hypothetical correlation of $\mathrm{CH}_{4}$ prediction equations obtained for given breeds and feeding system but apply to others, which could be as low as 0.80 .

\section{Conclusions and Perspectives}

In conclusion, when considering only the statistical calibration parameters of the 2 tested equations, the ILS equation provided numerically slightly better values regarding $\mathrm{R}^{2} \mathrm{c}$ and SEC than the DLS equation. However, it is very important to also take into account the behavior of the obtained indicators on real-life field data sets. When prediction equations were applied to a Walloon spectral data set, the observed results indicated that the DLS indicator better reflected biological processes than the ILS indicator. Moreover, on a completely independent data set (different breed, feeding, and $\mathrm{CH}_{4}$ measurement method), results indicated the clear superiority of the DLS compared with the ILS indicator and a lactation-stage based prediction (RLS indicator). These results also showed that the better fit of DLS throughout the lactation compared with ILS was due to it incorporating more information than only the lactation curve shape as does RLS.

The main objective of this study was to demonstrate the ability to incorporate lactation stage information in the $\mathrm{CH}_{4}$ prediction from MIR spectra. Based on these results, we can conclude that the novel DLS equation provided an adequate method to take into consideration the changes in expected metabolic status during lactation. In addition, the results of the present study suggest that the DLS equation enables development of $\mathrm{CH}_{4}$ indicators. Nevertheless, the accuracy and robustness of this equation still need to be enhanced and verified in other environments.

The DLS equation can be considered appropriate to predict a useful indicator of $\mathrm{CH}_{4}$ emission of dairy cows. However, the inclusion of additional reference data (e.g., other breeds, feeding systems) into the calibration set would increase the variability (at both $\mathrm{CH}_{4}$ and spectral levels) and consequently improve this equation as already shown for other MIR equations (e.g., Soyeurt et al., 2011). Based on the strategy used for FA, a typical cycle of updating the DLS equation would incorporate 3 steps. First, the existing equation will be tested on newly available $\mathrm{CH}_{4}$ reference data, simultaneously validating and harmonizing the corresponding MIR data. In the second step, predictions will be scrutinized and the new variability assessed to determine the relevant reference values that have to be added. After, most $\mathrm{CH}_{4}$ reference values would be added to the calibration data set. Finally, a new calibration will be developed and tested for its robustness. With increasing coverage of the variability, the changes in the equation in the updating process will be less and less important leading to fewer and less frequent updates of the DLS equation. A specific complication compared with other traits is that different methods exist to acquire $\mathrm{CH}_{4}$ reference values. Additional research will be needed to make the indicator robust in these circumstances. Moreover, further improvement of the DLS equation may also be achieved by adding relevant measurements of $\mathrm{CH}_{4}$ emission to the calibration data set which better cover the entire lactation. For example, as shown in Table 1, few data are available from very early in lactation (first $50 \mathrm{~d}$ ). Therefore, it would be interesting to add early lactation data to the calibration set.

The primary objective of this study was to test the usefulness of DLS coefficients. Therefore, the input variables were intentionally limited to using only MIR milk spectra and DIM information. The developed tool could be applicable routinely, for example in the milk-recording process where the milk analysis is often separated from the actual recording of yields. The next research steps should include other potentially useful 
traits (e.g., milk yield, DMI). This would also allow the link between $\mathrm{CH}_{4}$ and milk composition, as described by MIR spectral data, to be better separated, and to extend the reach of this research to feed energy loss and feed efficiency traits.

Finally, before including a $\mathrm{CH}_{4}$ indicator into any index to select for a (climate-smart) selection objective, additional research is required to establish the relationships between the $\mathrm{CH}_{4}$ indicator and other traits of interest.

\section{ACKNOWLEDGMENTS}

Financial support was provided by the Ministry of Agriculture of Walloon Region of Belgium (Service Public de Wallonie, Direction Générale Opérationnelle Agriculture, Ressources Naturelles et Environnement) through research projects D31-1248 and D31-1304. Nicolas Gengler, as a former senior research associate, acknowledges the support of the National Fund for Scientific Research (Brussels, Belgium). The authors thank the Walloon Breeding Association (Ciney, Belgium) for providing access to data related to the Walloon milk recording and the milk laboratory Comité du Lait (Battice, Belgium) for providing spectral data. The authors also acknowledge the support for this study provided by the FP7-PEOPLE-ITN-2008 238562 GreenhouseMilk. Frédéric Colinet (Gembloux Agro-Bio Tech, University of Liège, Gembloux, Belgium) is acknowledged for providing programs to calculate standardized Mahalanobis distances. The authors are grateful to the University of Liège (Service Général d'Informatique,, Liège, Belgium) for the use of their Numerically Intensive Computing 3 (NIC3) supercomputer. The Association of Swiss Cattle Breeders (Zollikofen, Switzerland) is acknowledged for providing funding to record the milk MIR spectral data of the Swiss samples. Finally, the authors thank the Mercator Research Program of the ETH Zurich World Food System Center for supporting the respiration chamber experiments.

\section{REFERENCES}

Aguerre, M. J., M. Wattiaux, J. M. Powell, G. Broderick, and C. Arndt. 2011. Effect of forage-to-concentrate ratio in dairy cow diets on emission of methane, carbon dioxide, and ammonia, lactation performance, and manure excretion. J. Dairy Sci. 94:30813093. http://dx.doi.org/10.3168/jds.2010-4011.

Berry, D. P., B. Horan, M. O'Donovan, F. Buckley, E. Kennedy, M. McEvoy, and P. Dillon. 2007. Genetics of grass dry matter intake, energy balance, and digestibility in grazing Irish dairy cows. J. Dairy Sci. 90:4835-4845.
Buehler, K., and M. Wanner. 2012. Chapter 6: Metabolic Centre of the University of Zurich and ETH Zurich (under construction). Pages 89-106 in Technical Manual on Respiration Chamber Designs. C. Pinares and G. Waghorn, ed. Ministry of Agriculture and Forestry, Wellington, New Zealand. Accessed April 2015. http:// www.globalresearchalliance.org/research/livestock/\%20activities/ knowledge/chamber-designs/.

Chilliard, Y., A. Ferlay, R. M. Mansbridge, and M. Doreau. 2000. Ruminant milk fat plasticity: nutritional control of saturated, polyunsaturated, trans and conjugated fatty acids. Ann. Zootech. 49:181-205. http://dx.doi.org/10.1051/animres:2000117.

Chilliard, Y., C. Martin, J. Rouel, and M. Doreau. 2009. Milk fatty acids in dairy cows fed whole crude linseed, extruded linseed, or linseed oil, and their relationship with methane output. J. Dairy Sci. 92:5199-5211. http://dx.doi.org/10.3168/jds.2009-2375.

Dehareng, F., C. Delfosse, E. Froidmont, H. Soyeurt, C. Martin, N. Gengler, A. Vanlierde, and P. Dardenne. 2012. Potential use of milk mid-infrared spectra to predict individual methane emission of dairy cows. Animal 6:1694-1701. http://dx.doi.org/10.1017/ S1751731112000456.

Dijkstra, J., S. M. van Zijderveld, J. A. Apajalahti, A. Bannink, W. J. J. Gerrits, J. R. Newbold, H. B. Perdok, and H. Berends. 2011. Relationships between methane production and milk fatty acid profiles in dairy cattle. Anim. Feed Sci. Technol. 166-167:590-595. http://dx.doi.org/10.1016/j.anifeedsci.2011.04.042.

Garnsworthy, P. C., J. Craigon, J. H. Hernandez-Medrano, and N. Saunders. 2012. Variation among individual dairy cows in methane measurements made on farm during milking. J. Dairy Sci. 95:3181-3189. http://dx.doi.org/10.3168/jds.2011-4606.

Gengler, N., A. Tijani, G. R. Wiggans, and I. Misztal. 1999. Estimation of (co)variance function coefficients for test day yield with a expectation-maximization restricted maximum likelihood algorithm. J. Dairy Sci. 82:1849.e1-1849.e23. http://dx.doi.org/10.3168/jds. S0022-0302(99)75417-2.

Johnson, K. A., and D. E. Johnson. 1995. Methane emissions from cattle. J. Anim. Sci. 73:2483-2492.

Mills, J. A. N., E. Kebreab, C. M. Yates, L. A. Crompton, S. B. Cammell, M. S. Dhanoa, R. E. Agnew, and J. France. 2003. Alternative approaches to predicting methane emissions from dairy cows. J. Anim. Sci. 81:3141-3150.

Misztal, I. 2012. BLUPF90 Family of Programs. Accessed April 2015. http://nce.ads.uga.edu/wiki/doku.php/.

Muñoz, C., T. Yan, D. A. Wills, S. Murray, and A. W. Gordon. 2012. Comparison of the sulfur hexafluoride tracer and respiration chamber techniques for estimating methane emissions and correction for rectum methane output from dairy cows. J. Dairy Sci. 95:31393148. http://dx.doi.org/10.3168/jds.2011-4298.

Soyeurt, H., F. Dehareng, N. Gengler, S. McParland, E. Wall, D. P. Berry, M. Coffey, and P. Dardenne. 2011. Mid-infrared prediction of bovine milk fatty acids across multiple breeds, production systems, and countries. J. Dairy Sci. 94:1657-1667. http://dx.doi. org/10.3168/jds.2010-3408.

Vallimont, J. E., C. D. Dechow, J. M. Daubert, M. W. Dekleva, J. W. Blum, C. M. Barlieb, W. Liu, G. A. Varga, A. J. Heinrichs, and C. R. Baumrucker. 2011. Heritability of gross feed efficiency and associations with yield, intake, residual intake, body weight, and body condition score in 11 commercial Pennsylvania tie stalls. J. Dairy Sci. 94:2108-2113. http://dx.doi.org/10.3168/jds.2010-3888.

van Zijderveld, S. M., B. Fonken, J. Dijkstra, W. J. J. Gerrits, H. B. Perdok, W. Fokkink, and J. R. Newbold. 2011. Effects of a combination of feed additives on methane production, diet digestibility, and animal performance in lactating dairy cows. J. Dairy Sci. 94:1445-1454. http://dx.doi.org/10.3168/jds.2010-3635.

Willmott, C., and K. Matsuura. 2005. Advantages of the mean absolute error (MAE) over the root mean square error (RMSE) in assessing average model performance. Clim. Res. 30:79-82. 